\title{
DOES STEROID PRETREATMENT INCREASE ENDOTOXIN RELEASE DURING CLINICAL CARDIOPULMONARY BYPASS?
}

Song Wan, MD, $\mathrm{PhD}^{\mathrm{a}}$

Jean-Louis LeClerc, MD $^{\mathrm{b}}$

Chi-Hoang Huynh, MD $^{\mathrm{b}}$

Denis Schmartz, MD

Jean-Marie DeSmet, MD ${ }^{\mathrm{b}}$

Anthony P. C. Yim, MD

Jean-Louis Vincent, MD $\mathrm{PhD}^{\mathrm{d}}$
Objective: The mechanism involved in the endotoxemia frequently recognized during cardiopulmonary bypass remains unclear. It has also been suggested that endotoxin levels were higher in steroid-pretreated patients undergoing cardiopulmonary bypass. Methods: Twenty patients undergoing cardiopulmonary bypass were randomly pretreated with steroids (methylprednisolone, $30 \mathrm{mg} / \mathrm{kg}$ ) or placebo. Blood samples for endotoxin measurement were drawn simultaneously from the superior and inferior venae cavae before heparin administration, 5 and 50 minutes after the onset of bypass, 5 minutes after aortic declamping, at the end of bypass, and 1, 2, and 20 hours after the end of cardiopulmonary bypass. Results: The perioperative variables in the two groups were similar. Blood endotoxin levels were higher in the inferior vena cava than in the superior vena cava immediately after the onset of bypass. Endotoxin levels in inferior vena cava blood were significantly lower in steroid-pretreated patients than those in patients not receiving steroids. Conclusions: Endotoxin is released during cardiopulmonary bypass from the region drained by the inferior vena cava. Steroid pretreatment may actually reduce endotoxin release during bypass. (J Thorac Cardiovasc Surg 1999;117:1004-8)
T ansient endotoxemia during clinical cardiopulmonary bypass (CPB) has been widely recognized. ${ }^{1-3}$ The phenomenon has been suggested to play an important role by increasing the generation of proinflammatory cytokines such as tumor necrosis factor- $\alpha^{4}$ and may subsequently result in postoperative complications., ${ }^{5,6}$ The source of endotoxin during $\mathrm{CPB}$, however, is still unclear. It has been suggested that endotoxin may be mainly released from the gut, because of increased intestinal permeability associated with splanchnic hypoperfusion during CPB. ${ }^{7-9}$ No direct evidence so far supports such an attractive hypothesis in the clinical setting. ${ }^{3}$

Corticosteroids have been used during cardiac operations with CPB for many years, but the mechanism of

From the Division of Cardiothoracic Surgery, ${ }^{a}$ Prince of Wales Hospital, The Chinese University of Hong Kong, Hong Kong, People's Republic of China, and Departments of Cardiac Surgery, ${ }^{\mathrm{b}}$ Anesthesiology, ${ }^{\mathrm{c}}$ and Intensive Care, ${ }^{\mathrm{d}}$ University Hospital Erasme, Free University of Brussels, Brussels, Belgium.

This study was supported by Fondation pour la Chirurgie Cardiaque, Belgium.

Received for publication June 11, 1998; revisions requested Oct 30, 1998; revisions received Jan 21, 1999; accepted for publication Jan 21, 1999

Address for reprints: Song Wan, MD, PhD, Division of Cardiothoracic Surgery, Department of Surgery, Prince of Wales Hospital, The Chinese University of Hong Kong, Shatin, NT, Hong Kong.

Copyright (C 1999 by Mosby, Inc.

0022-5223/99 $\$ 8.00+0 \quad \mathbf{1 2 / 1 / 9 7 3 7 5}$ this intervention is incompletely defined. ${ }^{3}$ Steroid administration has been suggested to inhibit ischemiareperfusion injury and to reduce the inflammatory response associated with $\mathrm{CPB},{ }^{10-13}$ but clinical benefits have not been conclusively demonstrated. Hence steroid pretreatment remains controversial. Moreover, it was suggested that steroid-treated patients might have greater blood endotoxin levels during CPB. ${ }^{14}$

This prospective, randomized study was designed to explore the possible relationship between steroid pretreatment and the degree of endotoxin release during clinical CPB. To help to define the source of endotoxin, we measured endotoxin levels in both venae cavae.

\section{Patients and methods}

In a 2-month period, 20 patients undergoing CPB for coronary artery bypass grafting $(\mathrm{CABG})$ or valvular operations were randomly divided into 2 groups receiving steroids or placebo. The study protocol was approved by the institutional review board. Written informed consent forms were obtained in all cases. Patients undergoing a potentially short duration of $\mathrm{CPB}$ such as for $\mathrm{CABG}$ of fewer than 3 grafts, those undergoing a redo or an emergency procedure, those who had infectious disease before the operation, and those who had used steroids in the preoperative period were not included. Hence 12 patients underwent minimally invasive direct $\mathrm{CABG}$ and another 65 patients who underwent $\mathrm{CPB}$ in the same period and who did not meet the inclusion criteria were excluded from the final study. For those patients who met the inclusion 
Endotoxin $(\mathrm{pg} / \mathrm{ml})$
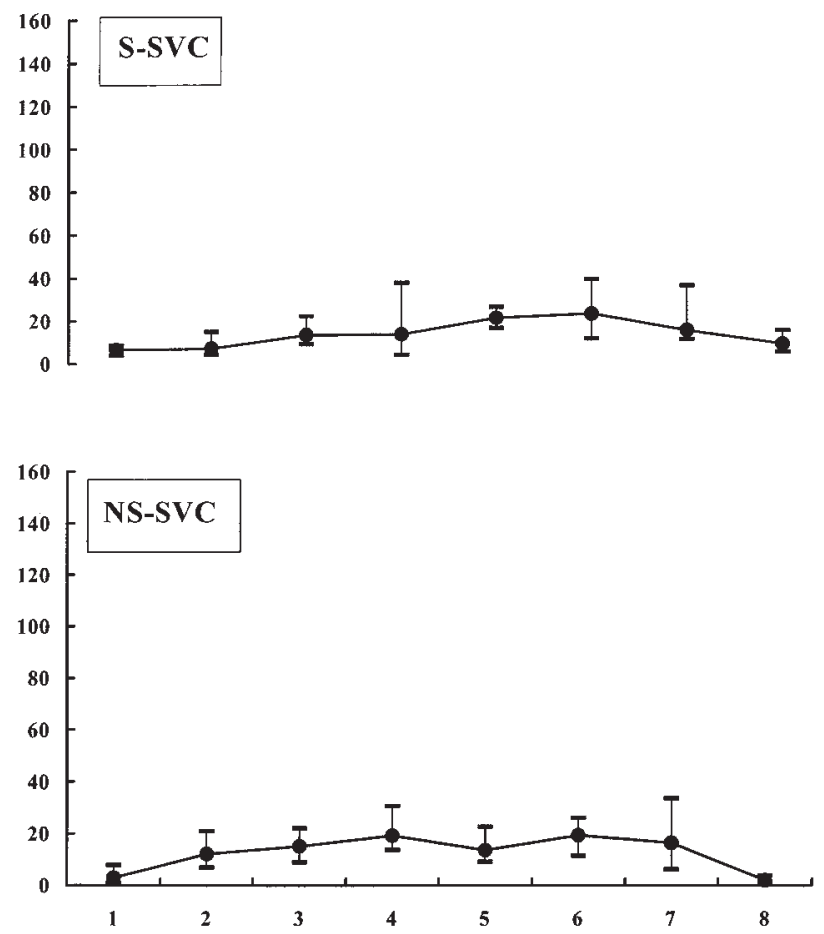
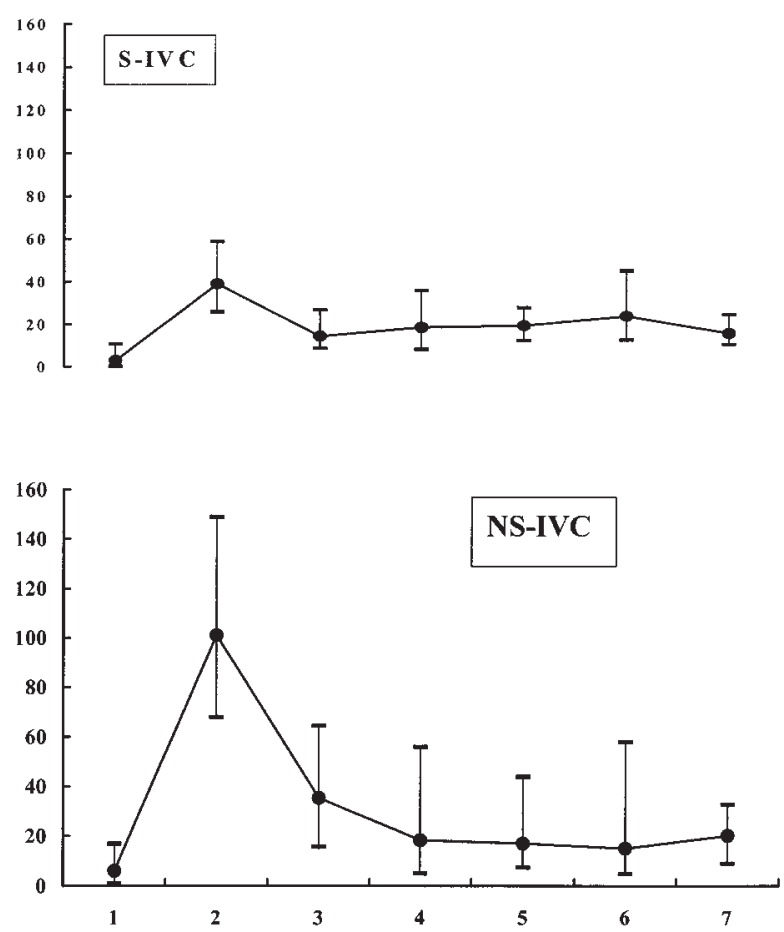

Fig 1. Endotoxin levels in SVC and IVC blood in patients undergoing CPB with (S-group, $n=10$ ) or without (NSgroup, $\mathrm{n}=10)$ steroid-pretreatment. Data are medians and interquartile ranges. For sampling time points, see text.

criteria, the type of treatment was determined by opening a sealed envelope prepared in advance. The preoperative characteristics in the 2 groups were similar.

All patients received a similar balanced anesthetic regimen, including sufentanil and midazolam. Relaxation was achieved with pancuronium. Cefuroxime (Zinacef; GlaxoWellcome Belgium) was given intravenously for prophylaxis at a dose of $1.5 \mathrm{~g}$ at induction of anesthesia, followed by $1.5 \mathrm{~g}$ every 12 hours for 48 hours. All patients received aprotinin (Trasylol; Bayer, Leverkusen, Germany) intravenously at a dose of 280 mg within 30 minutes of the beginning of the operation, 280 $\mathrm{mg}$ added to the prime of the circuit when starting $\mathrm{CPB}$, and $70 \mathrm{mg} / \mathrm{h}$ during CPB. Patients in the steroid pretreatment group (S-group) received a $30 \mathrm{mg} / \mathrm{kg}$ dose of methylprednisolone (Solu-Medrol; Pharmacia \& Upjohn, Kalamazoo, Mich) during induction of anesthesia. The other 10 patients in the placebo group (NS-group) did not receive steroids before, during, or after CPB.

The extracorporeal circuit consisted of a roller pump (Stöckert Instrumente GmbH, Munich, Germany) and a membrane oxygenator (Optima; Cobe Cardiovascular Inc, Arvada, Colo). Standard systemic heparinization $(3 \mathrm{mg} / \mathrm{kg}$ ) was accomplished and an activated clotting time of more than 480 seconds was maintained during CPB. The pump flow was set at $2.4 \mathrm{~L} / \mathrm{min}$ per square meter. All patients were cooled to between $30^{\circ} \mathrm{C}$ and $32^{\circ} \mathrm{C}$. Heparin was neutralized with protamine sulfate on discontinuation of CPB.
Blood samples for the measurements of endotoxin were collected simultaneously from the superior vena cava (SVC) through a standard central venous catheter introduced via the internal jugular vein and from inferior vena cava (IVC) through a femoral venous catheter that was inserted with fluoroscopic guidance after induction of anesthesia. The tips of both catheters were placed about $1.5 \mathrm{~cm}$ away from the respective caval opening to the right atrium. After the operation, their positions were confirmed again by radiography in the intensive care unit (ICU). The femoral venous catheter was withdrawn 2 hours after the end of CPB.

The blood sampling schedule was as follows: (1) just before heparin administration; (2) 5 minutes after the onset of CPB but before aortic crossclamping; (3) 50 minutes after the onset of CPB; (4) 5 minutes after aortic declamping; (5) at the end of CPB; and (6) 1 hour, (7) 2 hours, and (8) 20 hours after the end of CPB (except for IVC samples). Samples were collected in endotoxin-free tubes (EndoTube ET, with sodium heparin 120 IU; Chromogenix AB, Mölndal, Sweden), immediately cooled to $4^{\circ} \mathrm{C}$, and centrifuged ( $2800 g$ for 6 minutes at $4^{\circ} \mathrm{C}$ ). Plasma was stored at $-20^{\circ} \mathrm{C}$ until assay.

Postoperative serum creatine kinase $\mathrm{MB}$ and lactate values were measured every 12 hours within 24 hours. Postoperative blood losses, duration of mechanical ventilation, and the length of ICU stay were also recorded. The ICU staff was blinded as to the pretreatment of steroids.

Plasma endotoxin levels were measured with the Limulus 


\section{Endotoxin}

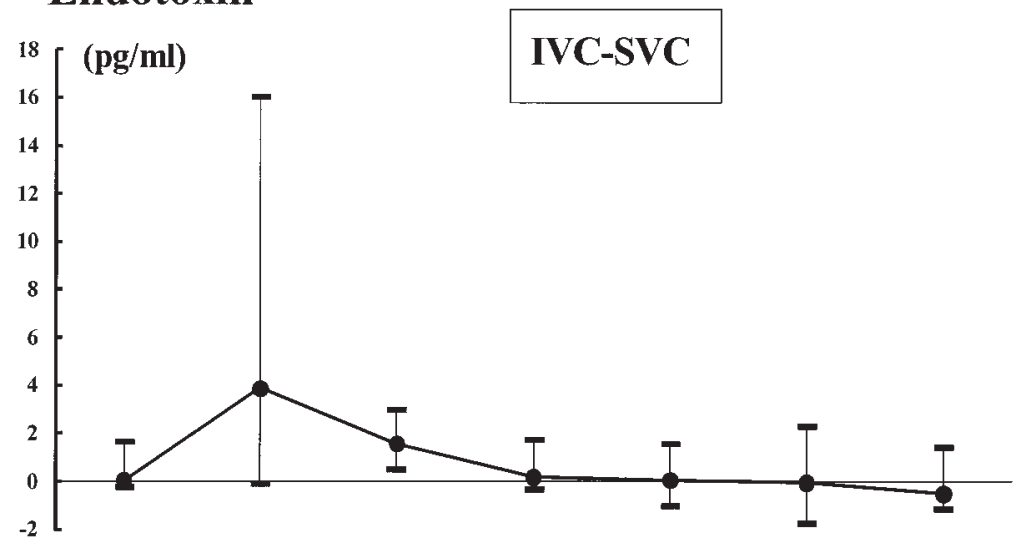

Fig 2. The IVC endotoxin values minus paired SVC values in 20 patients undergoing CPB. Data are medians and interquartile ranges. For sampling time points, see text.

Table I. Clinical data*

\begin{tabular}{lccc}
\hline & S-group & NS-group & P value \\
\hline No. of patients & 10 & 10 & $/$ \\
Male/female & $7 / 3$ & $7 / 3$ & $/$ \\
Age (y) & $65 \pm 10$ & $65 \pm 5$ & .93 \\
Body surface area $\left(\mathrm{m}^{2}\right)$ & $1.83 \pm 0.23$ & $1.87 \pm 0.18$ & .61 \\
Operative data & & & \\
$\quad$ CPB time (min) & $124 \pm 26$ & $123 \pm 36$ & .92 \\
$\quad$ Crossclamping time (min) & $93 \pm 24$ & $94 \pm 38$ & .95 \\
Postoperative data & & & \\
$\quad$ Peak CK-MB values (IU/L) & $36.6 \pm 26.7$ & $32.4 \pm 16.7$ & .68 \\
Peak lactate values (mmol/L) & $4.3 \pm 1.6$ & $2.9 \pm 1.4$ & .06 \\
$\quad$ Total chest tube drainage (mL) & $474 \pm 264$ & $505 \pm 177$ & .76 \\
Time on ventilator (h) & $14 \pm 7$ & $18 \pm 10$ & .32 \\
ICU stay (h) & $29 \pm 9$ & $32 \pm 23$ & .67 \\
\hline
\end{tabular}

$C P B$ : Cardiopulmonary bypass; $C K-M B$, creatine kinase isoenzyme $\mathrm{MB} ; I C U$, intensive care unit; S/NS-group, patients receiving/not receiving steroid pretreatment.

"Data are mean \pm standard deviation.

amebocyte lysate test (Coatest Plasma-Endotoxin; Endosafe Inc, Charleston, SC). The principle of this assay is that endotoxin activates a proenzyme in the Limulus amebocyte lysate. The activated enzyme split off para-nitro aniline from the chromogenic substrate S-2423 to produce a yellow color, which can be determined photometrically at $405 \mathrm{~nm}$. The end-point method was applied for endotoxin measurement, with each sample being tested in duplicate. The endotoxin concentration is presented as picograms per milliliter of plasma, with $1 \mathrm{pg}$ corresponding to 0.012 unit of endotoxin. No adjustment was made for hemodilution. Laboratory technicians were not aware of the clinical data.

The Mann-Whitney $U$ test was used for comparison of clinical data between 2 groups. Inasmuch as endotoxin values were not normally distributed, logarithm was applied. Data transformation was confirmed by the Kolmogorov-Smirnov test. Multivariate analysis was used to compare endotoxin levels between groups across time. Unbalanced repeatedmeasures models with first-order autoregressive covariance matrices (BMDP/Dynamic Program 5V, release 7, BMDP Statistical Software Inc, Los Angeles, Calif) were applied. The Wilcoxon signed-rank test was also used for comparison between paired SVC and IVC samples at a specific time point as appropriate. Clinical data are expressed as mean \pm standard deviation. Endotoxin values are presented as medians and interquartile ranges.

\section{Results}

Four patients in each group underwent combined procedures, namely, valve replacement with CABG. The intergroup differences were not statistically significant in terms of the operative and postoperative variables, including the levels of creatine kinase $\mathrm{MB}$ or lactate and the duration of mechanical ventilation or ICU stay (Table I). No patient required re-exploration for bleeding after the operation. All patients survived the hospital stay.

In both groups of patients, endotoxin levels increased immediately after the onset of CPB and tended to be higher in the IVC blood than in the SVC blood (Fig 1). There was no significant intergroup difference throughout the study period in SVC endotoxin levels $(P=.36$ for the group effect) and in their rates of change across time ( $P=.76$ for the interaction effect). However, IVC endotoxin levels were significantly higher in the NSgroup than in the $\mathrm{S}$-group $(P<.001$ for the group effect), although their trends of change were similar ( $P$ $=.28$ for the interaction effect).

The paired differences in endotoxin values between the 2 sites (IVC minus SVC, $\mathrm{n}=20$ ) are shown in Fig 2. Endotoxin levels in the IVC blood 5 minutes after the onset of CPB were higher than in the SVC blood ( $P$ $=.03$, by Wilcoxon signed-rank test). 


\section{Discussion}

Our study has two findings: First, endotoxin is released during $\mathrm{CPB}$ from the region drained by the IVC. Second, steroid pretreatment may actually reduce the release of endotoxin during CPB.

Transient endotoxemia during CPB has been observed for a decade ${ }^{1,2}$ and has occasionally been related to untoward effects in patients. 5 ,6 The pathogenesis involved in this phenomenon, however, is not entirely clear. For instance, the source of endotoxin during $\mathrm{CPB}$ remains to be fully defined. Two possible factors, exogenous and endogenous, have been incriminated. On the one hand, endotoxin has been detected in intraoperatively administered fluids. ${ }^{1}$ On the other hand, nonpulsatile perfusion during CPB may lead to gut mucosal ischemia, increase gut permeability, ${ }^{7-9}$ and result in endotoxin translocation into portal and systemic circulation. Exogenous endotoxin may also be a contributing trigger for gut release of endotoxin. ${ }^{15,16}$ Preoperative digestive decontamination has been suggested to reduce endotoxin levels after $\mathrm{CPB} .{ }^{17}$ Thus it was logical to speculate that the gut is a major source of endotoxin during $\mathrm{CPB}$.

However, direct supportive evidence for this hypothesis was lacking. By sampling hepatic venous and mixed venous blood in 10 patients undergoing CPB, Andersen and colleagues ${ }^{7}$ found identical changes in endotoxin concentrations in the systemic and splanchnic circulations. The increase in splanchnic endotoxin levels was even statistically insignificant compared with the baseline values. ${ }^{7}$ The authors ${ }^{7}$ could not show a correlation between the elevation of endotoxin levels and the fall in gastric intramucosal $\mathrm{pH}$. Riddington and coworkers ${ }^{9}$ reported increased intestinal permeability and raised endotoxin levels during CPB but were also unable to demonstrate any clear relationship between the two events. In both studies, ${ }^{7,9}$ intramucosal $\mathrm{pH}$ did not decrease until after the termination of CPB, suggesting that ischemia was not the prime cause for the increase in intestinal permeability. In addition, some investigators ${ }^{7,8}$ found that the increase in gut permeability was related to the duration of $\mathrm{CPB}$, but others did not. ${ }^{9}$ A positive correlation between the peak endotoxin level and both the duration of CPB and the duration of aortic crossclamping has been noted by some investigators, ${ }^{2}$ but not by others. ${ }^{18}$

Andersen and colleagues ${ }^{7}$ reported that the endotoxin concentrations did not differ in hepatic venous and mixed venous blood. Although they used a different analytic technique, including a rocket immunoelectrophoretic assay, endotoxin levels in the hepatic venous blood in their study were similar to those in the IVC blood in our study. However, endotoxin levels they mea- sured in the mixed venous blood were relatively high. ${ }^{7}$ This led us to compare the IVC blood samples with the premixed blood in the SVC. Our data, showing that endotoxin levels were higher in blood from the IVC than from the SVC, support the hypothesis that gut is an important source of endotoxin under $\mathrm{CPB}$ conditions.

The release of endotoxin has been described to be two-phased, a first peak occurring early after the onset of CPB and a second one after aortic declamping. ${ }^{4}$ The initial phase was explained by the presence of "environmental" exogenous endotoxin in the CPB circuit or pump prime solution. ${ }^{1,4}$ However, the higher endotoxin levels in the IVC blood after the onset of CPB, as observed in the current study, suggest that the gut may already be involved in the first part of endotoxin release. Jansen and associates ${ }^{19}$ proposed that endotoxin levels might be related to the degree of initial vasoconstriction and the degree of the hypo-oncotic state during CPB. It has also been postulated that the type of flow during CPB may play a role in inducing endotoxin release. Some investigators incriminated a nonpulsatile flow, 2,4 whereas Watarida and his associates ${ }^{20}$ reported that pulsatile flow might reduce endotoxin release. Nevertheless, the type of flow did not influence endotoxin levels during CPB in another randomized trial. ${ }^{21}$

Andersen and colleagues ${ }^{14}$ found that endotoxin levels were significantly higher after 90 minutes of CPB and at the end of CPB in 8 steroid-pretreated patients undergoing CABG than in control patients. No other study has been undertaken to confirm or refute this potentially critical conclusion. The effects of steroid pretreatment on inflammatory reactions associated with CPB have been recently reviewed. ${ }^{3,22}$ Previous studies documented that steroid treatment can significantly inhibit the production of endotoxin-induced cytokines in patients undergoing $\mathrm{CPB}$, such as tumor necrosis factor- $\alpha$, interleukin- 6 , and interleukin8. ${ }^{10-13,22}$ In a sheep heart transplantation model, steroid pretreatment has been reported to improve systolic and diastolic function and hemodynamic stability after $\mathrm{CPB} .^{23}$ Although not universally applied to clinical practice, steroid pretreatment has become a fundamental component of the so-called "fast-track recovery" protocol and has been suggested to improve postoperative recovery in patients after $\mathrm{CPB}$ and to reduce the length of stay in the ICU and in the hospital. ${ }^{24}$ In view of this reasoning, the relationship between steroid pretreatment and the degree of the regional release of endotoxin during CPB needed to be defined. Our results indicate that steroid pretreatment does not increase, but may actually reduce endotoxin release during $\mathrm{CPB}$. However, the findings from this pilot study still need to 
be confirmed in a larger trial, inasmuch as the multiple comparisons involved in data analysis may overstate the degree of statistical significance.

The involvement of the complex inflammatory response in perioperative injury has been recognized in patients undergoing CPB. ${ }^{3}$ It was proposed that mesenteric ischemia-reperfusion primes circulating neutrophils which, when activated by endotoxin, can result in distant organ damage. ${ }^{25}$ Although the exact role of endotoxin in this process remains elusive, ${ }^{26}$ a low preoperative level of immunoglobulin $\mathrm{M}$ endotoxin core antibody has been found to represent an independent predictor of adverse postoperative outcome in patients undergoing $\mathrm{CPB}^{27}$ and has been related to postoperative complications after cardiac valve surgery. ${ }^{28}$ Therefore, on the basis of a better understanding of the underlying pathogenesis, the development of efficient therapy aimed at limiting this inflammatory reaction may improve patient outcome.

We are indebted to Eric M. C. Wong, MA, and Joseph T. F. $\mathrm{Lau}, \mathrm{PhD}$, at Center for Clinical Trials and Epidemiological Research, The Chinese University of Hong Kong, for their valuable statistical advice.

\section{REFERENCES}

1. Andersen LW, Baek L, Degn H, Lehd J, Krasnik M, Rasmussen JP. Presence of circulating endotoxins during cardiac operations. J Thorac Cardiovasc Surg 1987;93:115-9.

2. Rocke DA, Gaffin SL, Wells MT, Koen Y, Brock-Utine JG. Endotoxemia associated with cardiopulmonary bypass. J Thorac Cardiovasc Surg 1987;93:832-7.

3. Wan S, LeClerc JL, Vincent JL. Inflammatory response to cardiopulmonary bypass: mechanisms involved and possible therapeutic strategies. Chest 1997;112:676-92.

4. Jansen NJG, van Oeveren W, Gu YJ, van Vliet MH, Eijsman L, Wildevuur CRH. Endotoxin release and tumor necrosis factor formation during cardiopulmonary bypass. Ann Thorac Surg 1992;54:744-8.

5. te Velthuis H, Jansen PGM, Oudemans-van Straaten HM, Sturk A, Eijsman L, Wildevuur CRH. Myocardial performance in elderly patients after cardiopulmonary bypass is suppressed by tumor necrosis factor. J Thorac Cardiovasc Surg 1995;110:1663-92.

6. Oudemans-van Straaten HM, Jansen PGM, te Velthuis H, et al. Increased oxygen consumption after cardiac surgery is associated with the inflammatory response to endotoxemia. Intensive Care Med 1996;22:294-300.

7. Andersen LW, Landow L, Baek L, Jansen E, Baker S. Association between gastric intramucosal $\mathrm{pH}$ and splanchnic endotoxin, antibody to endotoxin, and tumor necrosis factor- $\alpha$ concentrations in patients undergoing cardiopulmonary bypass. Crit Care Med 1993;21:210-7.

8. Ohri SK, Bjarnason I, Pathi V, et al. Cardiopulmonary bypass impairs small intestinal transport and increases gut permeability. Ann Thorac Surg 1993;55:1080-6.

9. Riddington DW, Venkatesh B, Boivin CM, et al. Intestinal permeability, gastric intramucosal $\mathrm{pH}$, and systemic endotoxemia in patients undergoing cardiopulmonary bypass. JAMA 1996;275: 1007-12.
10. Jansen NJG, van Oeveren W, van der Broek L, et al. Inhibition by dexamethasone of the reperfusion phenomena in cardiopulmonary bypass. J Thorac Cardiovasc Surg 1991;102:515-25.

11. Engelman RM, Rousou JA, Flack JE III, Deaton DW, Kalfin R, Das DK. Influence of steroids on complement and cytokine generation after cardiopulmonary bypass. Ann Thorac Surg 1995; 60:801-4.

12. Wan S, DeSmet JM, Antoine M, Goldman M, Vincent JL, LeClerc JL. Steroid administration in heart and heart-lung transplantation: Is the timing adequate? Ann Thorac Surg 1996;61:674-8.

13. Teoh KHT, Bradley CA, Gauldie J, Burrows H. Steroid inhibition of cytokine-mediated vasodilation after warm heart surgery. Circulation 1995;92(Suppl):II347-53.

14. Andersen LW, Baek L, Thomsen BS, Rasmussen JP. Effect of methylprednisolone on endotoxemia and complement activation during cardiac surgery. J Cardiothorac Anesth 1989;3:544-9.

15. O'Dwyer ST, Michie HR, Ziegler TR, et al. A single dose of endotoxin increases intestinal permeability in healthy humans. Arch Surg 1988;123:1459-64.

16. Fink MP, Antonsson JB, Wang H, Rothschild HR. Increased intestinal permeability in endotoxic pigs: mesenteric hypoperfusion as an etiologic factor. Arch Surg 1991;126:211-8.

17. Martinez-Pellús AE, Merino P, Bru M, et al. Can selective digestive decontamination avoid the endotoxemia and cytokine activation promoted by cardiopulmonary bypass? Crit Care Med 1993; 21:1684-91.

18. Nilsson L, Kulander L, Nyström SO, Eriksson Ö. Endotoxins in cardiopulmonary bypass. J Thorac Cardiovasc Surg 1990;100: 777-80.

19. Jansen PGM, te Velthuis H, Oudemans-van Straaten HM, et al. Perfusion-related factors of endotoxin release during cardiopulmonary bypass. Eur J Cardiothorac Surg 1994;8:125-9.

20. Watarida S, Mori A, Onoe M, et al. A clinical study on the effects of pulsatile cardiopulmonary bypass on the blood endotoxin levels. J Thorac Cardiovasc Surg 1994;108:620-5.

21. Taggart DP, Sundaram S, McCartney C, et al. Endotoxemia, complement, and white blood cell activation in cardiac surgery: a randomized trial of laxatives and pulsatile perfusion. Ann Thorac Surg 1994;57:376-82.

22. Wan S, LeClerc JL, Vincent JL. Cytokine responses to cardiopulmonary bypass: lessons learned from cardiac transplantation. Ann Thorac Surg 1997;63:269-76.

23. Segel LD, Follette DM, Castellanos LM, Hayes R, Baker JM, Smolens IA. Steroid pretreatment improves graft recovery in a sheep orthotopic heart transplantation model. J Heart Lung Transplant 1997;16:371-80.

24. Engelman RM, Rousou JA, Flack JE III, et al. Fast-track recovery of the coronary bypass patient. Ann Thorac Surg 1994;58: 1742-6.

25. Moore EE, Moore FA, Franciose RJ, Kim FJ, Biffl WL, Banerjee A. The postischemic gut serves as a priming bed for circulating neutrophils that provoke multiple organ failure. J Trauma 1994; 37:881-7.

26. Kelly JL, O'Sullivan C, O'Riordain M, O'Riordain D, Lyons A, Doherty $\mathrm{J}$, et al. Is circulating endotoxin the trigger for the systemic inflammatory response syndrome seen after injury? Ann Surg 1997;225:530-43.

27. Bennett-Guerrerro E, Ayuso L, Hamilton-Davies C, et al. Relationship of preoperative antiendotoxin core antibodies and adverse outcomes following cardiac surgery. JAMA 1997;277:646-50.

28. Hamilton-Davies C, Barclay GR, Cardigan RA, et al. Relationship between preoperative endotoxin immune status, gut perfusion, and outcome from cardiac valve replacement surgery. Chest 1997;112:1189-96. 